\title{
Metabolic effects of parasitization by the barnacle Polyascus plana (Cirripedia: Rhizocephala: Sacculinidae) on a grapsid host, Metopograpsus thukuhar
}

\author{
Chia-Jen Hsiao ${ }^{1, *}$, Yen-I Wu ${ }^{2, *}$, Tzu-An Tung ${ }^{2}$, Guan-Yi Wang ${ }^{2}$, Jean-Yves Toullec ${ }^{3,4}$, \\ Shih-Ting Liu ${ }^{2}$, Wen-San Huang ${ }^{5,6}$, Chi-Ying Lee ${ }^{2, * *}$
}

\begin{abstract}
${ }^{1}$ Division of Gastroenterology, Department of Internal Medicine, Taoyuan Armed Forces General Hospital, Taoyuan 32551, Taiwan ${ }^{2}$ Department of Biology, National Changhua University of Education, Changhua 50058, Taiwan

${ }^{3}$ Sorbonne Universités, UPMC Université Paris 06, UMR 7144 CNRS, Equipe ABICE, Station Biologique de Roscoff, Roscoff, France ${ }^{4}$ CNRS, UMR 7144, Adaptation et Diversité en Milieu Marin, Station Biologique de Roscoff, Roscoff, France

${ }^{5}$ Department of Biology, National Museum of Natural Science, Taichung 40453, Taiwan

${ }^{6}$ Department of Life Sciences, National Chung Hsing University, Taichung 40254, Taiwan
\end{abstract}

\begin{abstract}
Pathophysiological studies of rhizocephalan infections are rare. We describe differences in the levels of tissue and hemolymph metabolites between Polyascus plana-parasitized and unparasitized individuals of Metopograpsus thukuhar. Crabs were assigned to either a parasitized (carrying at least 1 externa, i.e. a protruding reproductive body) or an unparasitized (not carrying externae and determined to be rootlet-free by a barnacle $18 \mathrm{~S}$ rRNA-based polymerase chain reaction) group. Quantification of metabolites showed that muscle glycogen levels were significantly lower and hepatopancreas levels were significantly higher in parasitized crabs compared to unparasitized crabs; hepatopancreas triacylglycerol levels were significantly higher and hemolymph levels significantly lower in parasitized hosts, and there was no significant difference in muscle triacylglycerol levels between unparasitized and parasitized animals. Glucose levels in the hepatopancreas, muscle, and hemolymph were all significantly higher in parasitized hosts. Significant levels of glucose, triacylglycerol, and glycogen were present in the barnacle externae. In addition, levels of crustacean hyperglycemic hormone in the sinus glands were not significantly different between unparasitized and parasitized animals. Glucose mobilized from the muscle is likely converted to glycogen and triacylglycerol in the rootlet-infiltrated hepatopancreas of parasitized hosts, and the eyestalk neuroendocrine system appears not to be significantly impaired, in terms of hormone production and storage, by parasitization.
\end{abstract}

KEY WORDS: Parasitism $\cdot$ Rhizocephala $\cdot$ Metabolism $\cdot$ Crustacean hyperglycemic hormone

\section{INTRODUCTION}

The Rhizocephala comprise a taxon of highly specialized barnacles that parasitize a wide array of crustacean hosts. In their life cycle, the nauplii, i.e. pelagic larvae released from the adult rhizocephalan parasites, develop into cyprid larvae. Female cyprids attach and settle on a host and metamorphose into a kentro-

\footnotetext{
*These 2 authors contributed equally to this work
}

${ }^{* *}$ Corresponding author: bicylee@cc.ncue.edu.tw gon, which injects parasitic material into the host through a hollow cuticular structure (the stylet) that penetrates into the host (see Høeg 1995 for review). For at least 2 sacculinid rhizocephalans (Loxothylacus texanus and $L$. panopaei), the injected vermiform body was shown to be a distinct instar, called the vermigon (Glenner et al. 2000, Glenner 2001). After being injected into the host, the vermigon ramifies

() The authors 2016. Open Access under Creative Commons by Attribution Licence. Use, distribution and reproduction are unrestricted. Authors and original publication must be credited. 
throughout the hemocoel and develops into an internal rootlet system - the interna - that absorbs nutrients from the hemolymph of the host (Glenner \& Høeg 1995, Glenner et al. 2000, Glenner 2001). When fully developed, the parasite also has a protruding reproductive body, the externa, which is contiguous with the interna via a connecting stalk and is visible on the ventral surface of the abdomen of the host. The externa is morphologically reduced, consisting of a muscular mantle housing a brood chamber and a visceral sac with an ovary (Høeg 1995, Walker 2001). During the parasitic phase, rhizocephalans rely on the host for nutrients that are absorbed through the rootlet system, and, as such, must place an enormous metabolic burden on the host. However, only a few studies have examined changes in the metabolic profile of the host in response to parasitization by rhizocephalans (Smith 1911, Drilhon 1936, Shirley et al. 1986, Powell \& Rowley 2008; also see Høeg 1995).

One of the fascinating features of rhizocephalan parasitism is the host control exerted by the parasite. In its most extensive form of control involving parasitization by sacculinid rhizocephalans, the parasitized host undergoes profound behavioral, morphological, and physiological changes, including retardation of the growth and molt cycle, feminization of male hosts, and parasitic sterilization (reviewed by O'Brien \& van Wyk 1985, Høeg 1995, O'Brien 1999, Walker 2001).

Eight species of rhizocephalans, belonging to 4 genera (Thylacoplethus, Diplothylacus, Sacculina, and Heterosaccus), have been described from Taiwanese waters (Huang \& Lützen 1998). Among these, Polyascus plana (Glenner et al. 2003) is an abundant species that infects several species of brachyurans with a wide geographical distribution (Huang \& Lützen 1998, Liu \& Lützen 2000). Development and sex ratio of the larvae of $P$. plana, released from the externae on the parasitized Grapsus albolineatus, have been studied (Tu et al. 2009). Moreover, the prevalence of infection of $P$. plana on Metopograpsus thukuhar and developmental changes in the externa were recently reported (Hsu 2014). The objectives of the present study were to examine the effects of parasitization by $P$. plana on the metabolic profile of $M$. thukuhar and to provide data with which control of the host by rhizocephalans could be elucidated by future investigations on the aspects of pathophysiological changes in the host.

\section{MATERIALS AND METHODS}

\section{Animals}

Crabs (Metopograpsus thukuhar Owen, 1839; $\mathrm{n}=$ 35 in total) were collected from intertidal zones of the Da'an estuary $\left(24.36^{\circ} \mathrm{N}, 120.58^{\circ} \mathrm{E}\right)$, Taichung, Taiwan, and visually checked for the presence or absence of externae on the ventral side of the abdomen. Crabs with or without externae (Fig. 1) were transported in separate containers to the National Changhua University of Education, where they were maintained for $2 \mathrm{~d}$ in seawater tanks with a salinity of $25 \%$ at $25 \pm 2{ }^{\circ} \mathrm{C}$ and constant aeration.

Adult crabs with a carapace width larger than $2 \mathrm{~cm}$ were used in the experiments. The parasitized animals described in the present study were those carrying at least 1 externa. The unparasitized animals were those with no externae; furthermore, the thoracic ganglia of these animals were determined to be free of rootlets of the parasite using a polymerase chain reaction (PCR) with a pair of primers based on the18S rRNA gene of the parasite (see 'PCR' below).

\section{Tissue sampling and processing}

A group of animals (16 animals including 6 with externae and 10 without externae) was used for tissue sampling to be analyzed by PCR amplification (see 'PCR' below), histological observation (see 'Histology' below), and immunoassay (see 'ELISA' be-
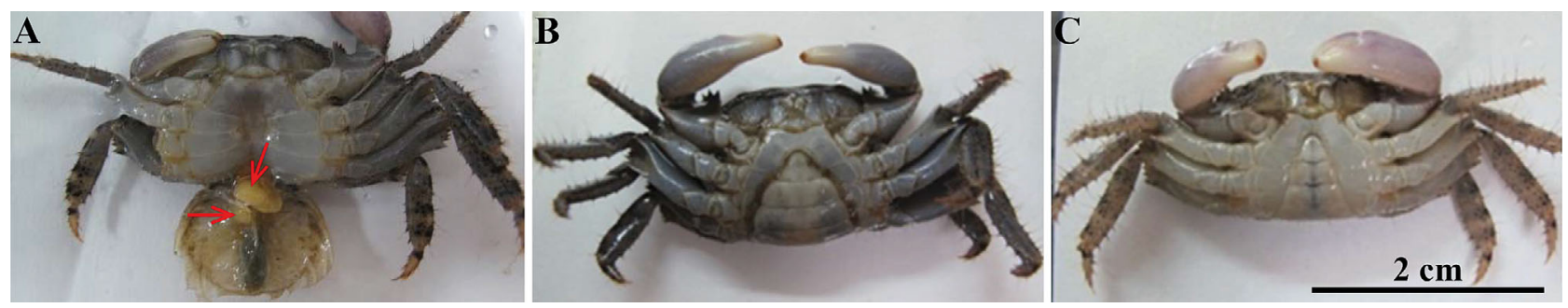

Fig. 1. Externae of Polyascus plana on parasitized crabs Metopograpsus thukuhar and characteristics of a feminized abdomen.

(A) Externae (red arrows) located on the ventral surface of a parasitized female. (B) Parasitized male with a broad abdomen. (C) Unparasitized crab with a characteristic male abdomen shown for comparison. Scale bar applies to (A), (B), and (C) 
low). Animals were anesthetized with cold seawater $\left(0^{\circ} \mathrm{C}\right)$ and dissected for tissue sampling, including the thoracic ganglia, hepatopancreas, muscle, eyestalk ganglia, and, where applicable, externae. Pieces of tissues (thoracic ganglia, hepatopancreas, and muscle) were placed in Davidson's seawater fixative until used for histological staining and observation, whereas the remaining thoracic ganglia and muscle samples, as well as the externae, were used for PCR amplification. The sinus glands were completely removed from the dissected eyestalk ganglia, homogenized in 0.1 M HEPES (4-(2-hydroxyethyl)-1-piperazineethanesulfonic acid)-buffered crab saline, $\mathrm{pH}$ 7.6, and centrifuged at $16000 \times g\left(30 \mathrm{~min}\right.$ at $\left.4^{\circ} \mathrm{C}\right)$; the supernatants were stored at $-80^{\circ} \mathrm{C}$ until quantified for levels of crustacean hyperglycemic hormone (CHH).

A second group of animals (12 animals including 6 parasitized and 6 unparasitized crabs) was used in biochemical assays for metabolites in tissue and hemolymph (see 'Biochemical assays for tissue and hemolymph metabolites' below). Anesthetized animals were bled from the periarthrodal membrane at the base of pereiopods (pre-sterilized with $70 \%$ ethanol) using a syringe with a $26-\mathrm{G}$ needle, prior to dissection for tissues. Withdrawn hemolymph was diluted 3:1 (V:V) with an anti-coagulant (0.1 M EDTA in Pantin's crab saline, pH 7.6; Pantin 1934) and centrifuged at $2000 \times g\left(20 \mathrm{~min}\right.$ at $\left.4^{\circ} \mathrm{C}\right)$; the resulting supernatant was collected and stored at $-80^{\circ} \mathrm{C}$ until used for subsequent biochemical assays. Tissues, including the hepatopancreas, muscle, and externae, were dissected from the animals. Individual host tissues ( 100 mg) and externae ( $\sim 50-60 \mathrm{mg})$ were homogenized using sonication in $200 \mu$ l of water (except when assaying triacylglycerol levels, for which $1.0 \mathrm{ml}$ of $5 \%$ IGEPA, I3021 Sigma, was used) and heated at $100^{\circ} \mathrm{C}$ for $5 \mathrm{~min}$ using a hot plate. The homogenates were then centrifuged at $20000 \times g\left(20 \mathrm{~min}\right.$ at $\left.4^{\circ} \mathrm{C}\right)$, and the resulting supernatants were collected and stored at $-80^{\circ} \mathrm{C}$ until used for subsequent biochemical assays.

\section{PCR}

To determine the presence (or absence) of rootlets of the parasite in the crab tissues, the thoracic ganglia, muscle, and externae were dissected from animals ( 6 with externae and 10 without externae) for extraction of genomic DNA using a Blood and Tissues Genomic DNA isolation kit (Viogene), with reagents and a protocol provided by the manufacturer (Chen et al. 2007). A pair of PCR primers, Sac18s
rRNA-F1 (5'-CGG ATT GCT GGT TGA CAT CGT T3') and Sac18s rRNA-R1 (5'-GCG GTT AAA AAG CTC GTA GTT GG-3'), was designed based on an 18S rRNA gene (GenBank accession number AY265368) of the parasite; the sequences of the primers are highly conserved among the 18S rRNA genes of Polyascus species (AY265363, AY265362) and Sacculina species (AY265366, AY265360, AY265360) (Glenner et al. 2003). The genomic DNA $(0.5 \mu \mathrm{g})$ was amplified using the primer pair and the reagents provided in the GoTaq ${ }^{\circledR}$ DNA Polymerase kit (Promega), with the amplification parameters set as an initial denaturation $\left(3 \mathrm{~min}, 95^{\circ} \mathrm{C}\right), 35$ cycles of denaturation $\left(30 \mathrm{~s}, 95^{\circ} \mathrm{C}\right)$, annealing $\left(30 \mathrm{~s}, 52^{\circ} \mathrm{C}\right)$, and extension $\left(1 \mathrm{~min}, 72^{\circ} \mathrm{C}\right)$, followed by a final extension $(7 \mathrm{~min}$, $72^{\circ} \mathrm{C}$ ). After PCR, an aliquot of the reaction was separated on a $1.2 \%$ agarose gel and visualized with GelStar ${ }^{\circledR}$ (Cambrex). Reagents and procedures used for purification and auto-sequencing of the PCR products, as well as software resources for sequence analyses, were as described by Chen et al. (2007).

\section{Histology}

Tissues (thoracic ganglia, hepatopancreas, and muscle), fixed in Davidson's seawater fixative, were dehydrated through an alcohol series, embedded in paraffin (Paraplast ${ }^{\circledR}$, Leica), and cut into $5 \mu \mathrm{m} \mathrm{sec-}$ tions. Tissue sections were then deparaffinated, rehydrated, and stained with Harris' hematoxylin and eosin following established protocols (Johnson 1980).

\section{Indirect enzyme-linked immunosorbent assay (ELISA)}

Sinus gland homogenates were analyzed by an indirect ELISA for the levels of CHH. The reagents (excepting the primary antibody), experimental protocol, and data processing for the ELISA followed the methods described by Lee et al. (2001). The primary antibody used was the IgG fraction of an antibody (anti$\mathrm{Sco}-\mathrm{CHH}$ ), which was raised against a C-terminal stretch (residues 59-71) of the mud crab Scylla olivacea $\mathrm{CHH}$, Sco-CHH (Tsai et al. 2008). Specificity of the primary antibody for the putative $\mathrm{CHH}$ in the sinus gland samples of $M$. thukuhar was assessed by 2 tests. First, samples were assayed with the ELISA using the anti-Sco-CHH pre-adsorbed with the synthetic peptide that was used for raising the antibody (Tsai et al. 2008). Second, instead of using the anti-Sco-CHH antibody, sinus gland samples were assayed using the 
IgG fraction of the pre-immune serum. Samples thus assayed yielded values of optical density (preadsorbed serum: $0.35 \pm 0.11 \mathrm{SE}, \mathrm{n}=5$; pre-immune serum: $0.33 \pm 0.07, \mathrm{n}=5$ ) not statistically different from background reading $(0.27 \pm 0.04, n=5)$, suggesting that anti-Sco-CHH specifically binds $\mathrm{CHH}$ in the sinus gland samples of $M$. thukuhar. Purified Sco$\mathrm{CHH}$ (Chang et al. 2010) was used for constructing the standard curve, from which the $\mathrm{CHH}$ levels in sinus gland samples of $M$. thukuhar were estimated.

\section{Biochemical assays for tissue and hemolymph metabolites}

The tissue and hemolymph samples collected as mentioned above were quantitatively assayed for glycogen (Glycogen Colorimetric/Fluorometric Assay Kit, K646-100, BioVision), triacylglycerol (Triglyceride Quantification Colorimetric/Fluorometric Kit, BioVision), and glucose (Glucose Assay Kit, GAGO20, Sigma). All 3 assays were performed in a microplate format using reagents provided by the kits and following the manufacturer's protocol for each assay. Reactions were read colorimetrically using a microplate reader ( $\mu$ Quant, BioTek) at $570 \mathrm{~nm}$, excepting those of the glucose assay which were read at $540 \mathrm{~nm}$. Standards for each assay were assayed concurrently with the samples for construction of the standard curve, from which the levels of each analyte in the samples were estimated. For each assay, wells ( $\mathrm{n}=$ 3 per plate) serving as backgrounds (without standard or sample) were also assayed concurrently to obtain background readings. The assay sensitivity (i.e. the lowest amounts of each analyte giving an optical density reading significantly greater than background) was $\sim 0.17 \mu \mathrm{g}$ well $^{-1}$, $0.77 \mathrm{nmol} \mathrm{well}^{-1}, 0.43 \mathrm{nmol}$ well ${ }^{-1}$ for glycogen, triacylglycerol, and glucose, respectively.

\section{Statistical analysis}

Differences between the parasitized and unparasitized crabs in each measured parameter were analyzed by Student's t-test using computer software (SPSS Manager, SPSS).

$B$

\section{RESULTS}

Experimental animals were first divided into those carrying at least 1 externa on the ventral surface of the abdomen (Fig. 1A) or those without. Externa-carrying males usually have a broad abdomen (Fig. 1B) that resembles the female abdomen in shape, in contrast to the triangular abdomen of a normal male (Fig. 1C).

Results of PCR amplification of genomic DNA extracted from crabs revealed an amplicon (expected size of the amplicon: $486 \mathrm{bp}$ ) present in all of the thoracic ganglia samples from the externa-carrying crabs, as well as in the externa samples (Fig. 2A); an amplicon of the same electrophoretic mobility was also detected in the thoracic ganglia derived from some, but not all, of the crabs without externae (Fig. 2A); hence, they were considered infected with the internal stage of the parasite. The sequence of all amplicons is identical to the stretch of sequence of the 18S rRNA gene bracketed by the primers (Fig. 2B). In contrast, amplification of the muscle samples, derived from animals either with or without externae, gave negative results (Fig. 2A).

Histological observation of crab tissues revealed the presence of rootlets in all of the thoracic ganglia dissected from the externa-carrying crabs, and the

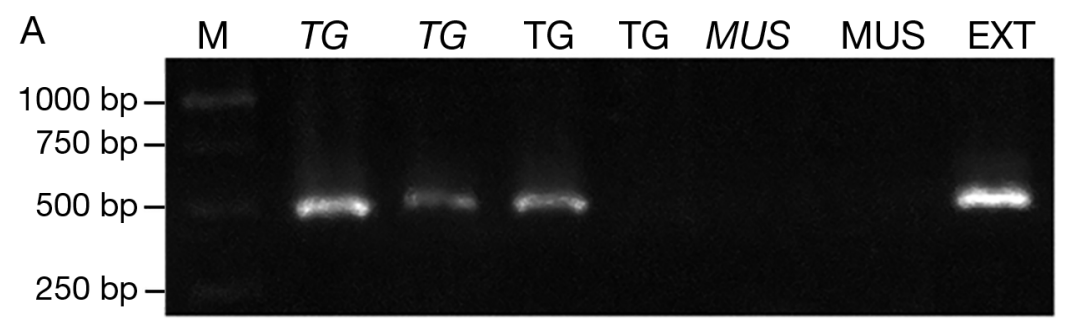

CGGATTGCT GGTTGACAT CGTTACGG TTAGAACTA GGGCGGTAT CTGATCGCC TTCGAACCT CTAACTTTC GTTCTTGAC TAATGAAAA CATTCTCGG CAAATGCTT TCGCAGTAG TTCGTCGTG CAACGGTCC TAGGATTTC ACCCCTCGC GCTGACCAA CCAAATTGA GTCAGGGAC GTATTCTCC AATTCCATG AATATGTAT TCAGGCAAA CATCGCCTG CTTTAAGCA CTCTAATTT GTTCAAGGT AATATCGCC GGTCGCCGA CAGGCCCCT CCGAAACGG AACGGCCCG ACAACGGAT CCGACACTT TTGAATGCG GCCAGCCGA TATTTAGAG CACGCCACC GGTGCGCTG TTACACGAC ACCGATGAA CGCGCATAC CGGACGTGG ACACGCACT GATATCCAA CTACGAGCT TTTTAACCG CAA

Fig. 2. Detection of a sacculinid 18S rRNA gene in the tissues of Metopograpsus thukuhar: (A) thoracic ganglia (TG), muscle (MUS), and externae (EXT). M indicates the size marker (in base pairs, bp). Italics indicate tissues from externae-carrying crabs; normal font indicates tissues from crabs not carrying externae. (B) Sequence of nucleotides 756 to 1241 of the 18S rRNA gene amplified by the primers. Underlined stretches indicate the nucleotide sequences corresponding to the forward and reverse primers 
hepatopancreases of these animals were usually heavily infiltrated by rootlets (Fig. 3A,B). For crabs not carrying externae, histological examinations confirmed PCR results - rootlets were found infiltrating the thoracic ganglia of the crabs that were positive for the sacculinid 18S rRNA gene (Fig. 3C), but were not found infiltrating those negative for the 18S rRNA gene (Fig. 3D). In contrast, rootlets were absent from
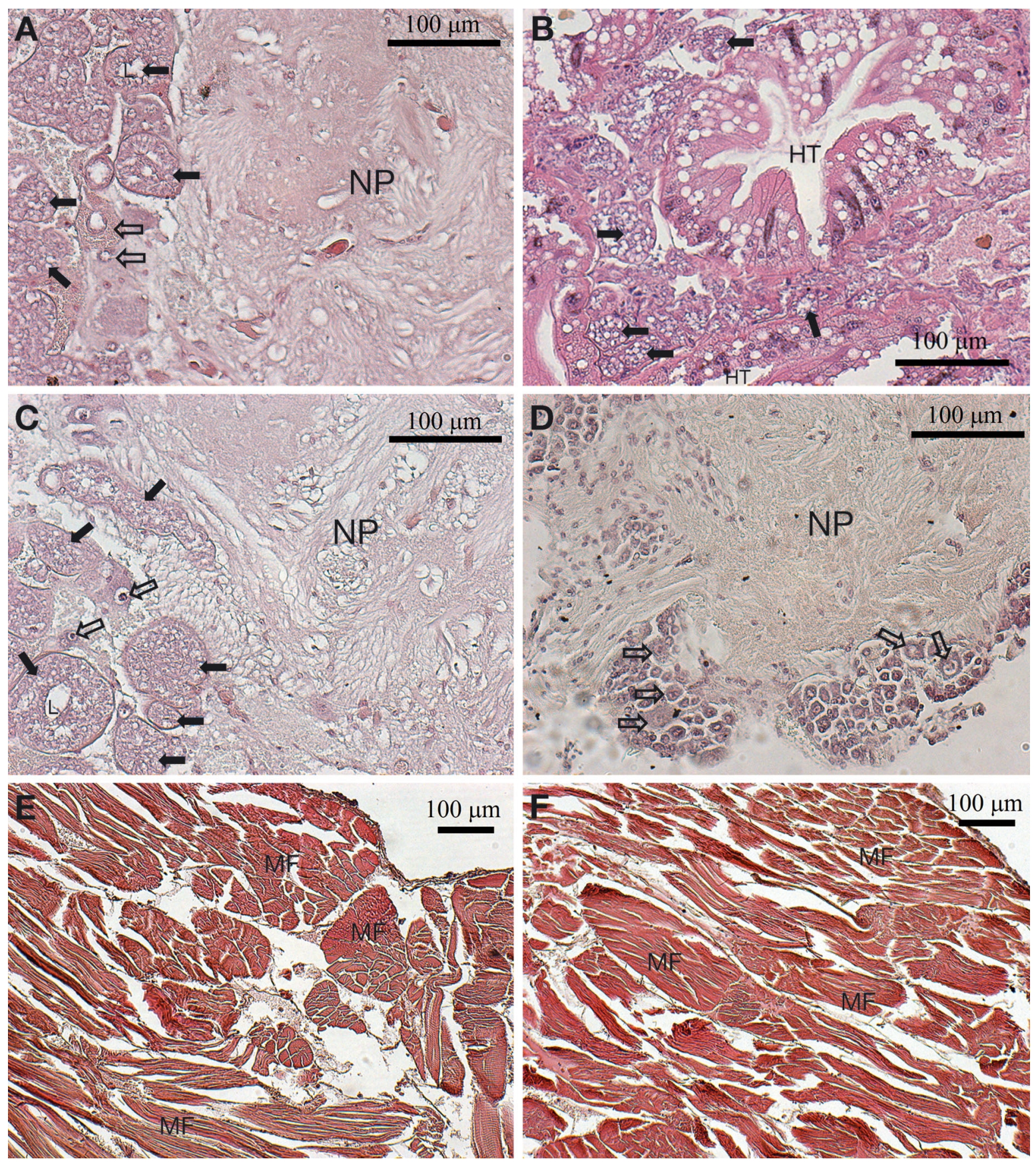

Fig. 3. Histological observations of the tissues of Metopograpsus thukuhar. Sections of (A) the thoracic ganglia and (B) hepatopancreas of an externa-carrying crab showing heavily infiltrating rootlets. (C) Presence or (D) absence of rootlets in thoracic ganglia of crabs not carrying externae. Absence of rootlets in muscle of (E) an externa-carrying crab and (F) a crab not carrying externae. HT: hepatopancreatic tubules; L: lumen of the rootlet; MF: muscle fibers; NP: neuropil area. Neurosecretory cells of the thoracic ganglia are indicated by open arrows and infiltrating rootlets by solid arrows. Note the clusters of well-organized neurosecretory cells in the peripheral regions of the thoracic ganglia (in D) and the disintegration of the clustering and significant reduction in the number of neurosecretory cells (in A and C) 

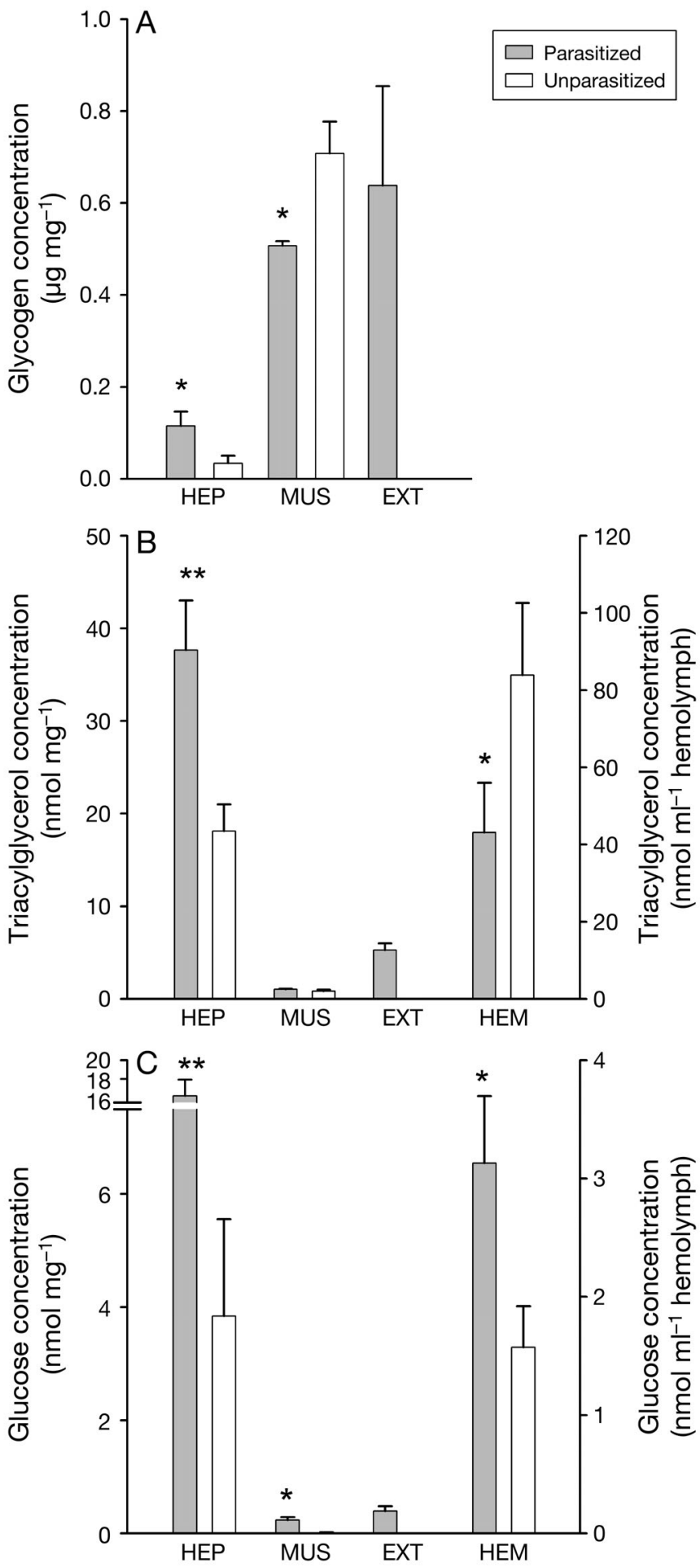

Fig. 4. Metabolites in tissues (HEP: hepatopancreas; MUS: muscle, and EXT: externa) and hemolymph (HEM) of parasitized and unparasitized Metopograpsus thukuhar: (A) glycogen, (B) triacylglycerol, (C) glucose. Gray bars: parasitized animals or externae; white bars: unparasitized animals. Data are the mean \pm SEM ( $n=6$ for each data point). ${ }^{*},{ }^{* *}$ represent significant differences between parasitized and unparasitized groups at $\alpha=0.05$ and 0.01 , respectively

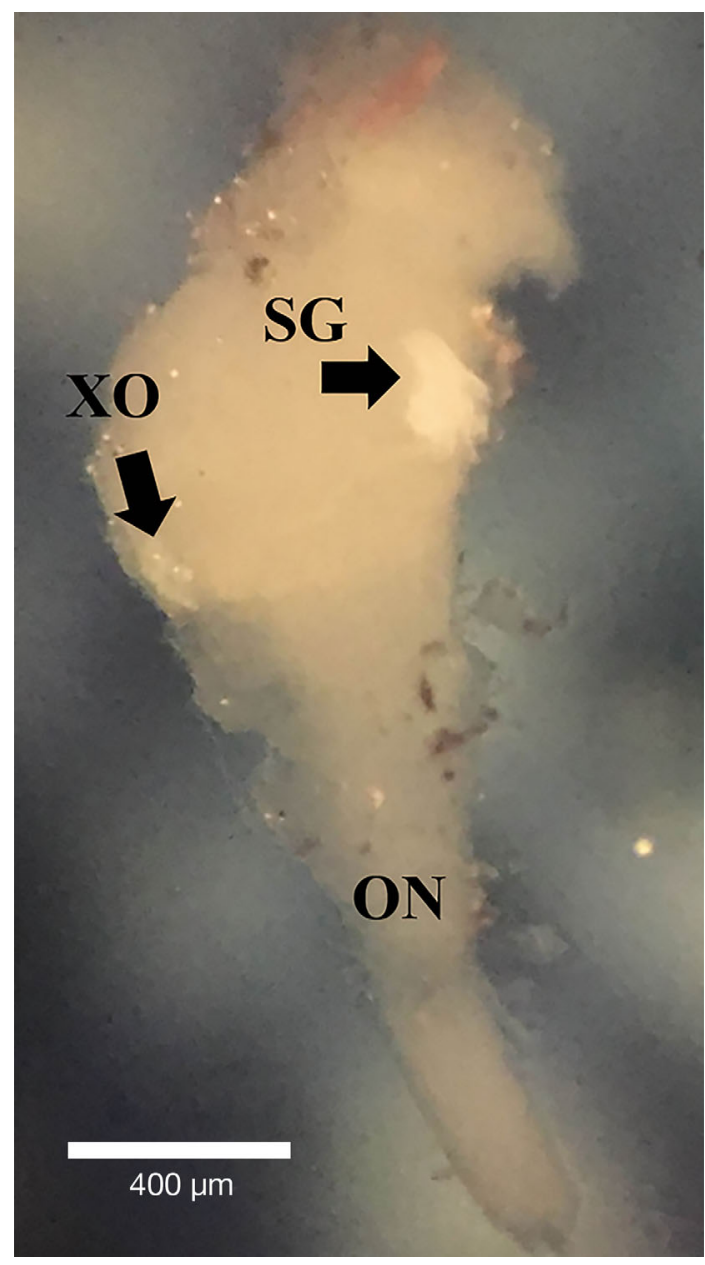

Fig. 5. X-organ/sinus gland complex in the eyestalk of parasitized Metopograpsus thukuhar. Eyestalk ganglia dissected from an eyestalk of a parasitized crab show a cluster of neurosecretory somata (the X-organ, XO) and its neurohemal organ (the sinus gland, SG); ON: optic nerve

the muscle of crabs with or without externae (Fig. 3E,F, respectively), again corroborating PCR data.

Metabolic profiles of parasitized and unparasitized Metopograpsus thukuhar were distinctly different from each other. Compared to unparasitized crabs, hepatopancreas glycogen levels were significantly higher and muscle glycogen levels were significantly lower in parasitized crabs (Fig. 4A). Parasitized crabs had significantly higher levels of triacylglycerol in the hepatopancreas and significantly lower levels in the hemolymph than unparasitized crabs; however, muscle levels were not statistically different between parasitized and unparasitized animals (Fig. 4B). The glucose levels in the hepatopancreas, muscle, and hemolymph were all significantly higher in parasitized crabs than in unparasitized crabs (Fig. 4C). Glycogen, triacylglycerol, and glucose levels in the 
externae were also measured and are presented for comparison with those in host tissues (Fig. 4A-C).

We found no significant difference in the $\mathrm{CHH}$ levels between parasitized and unparasitized crabs $(0.15 \pm 0.04$ SE vs. $0.11 \pm 0.01$ pmol per sinus gland; $\mathrm{n}=6$ in each group). The X-organ/sinus gland complex in the eyestalk ganglia of parasitized crabs appeared morphologically intact (Fig. 5).

\section{DISCUSSION}

The metabolic profile of a parasitized host, Metopograpsus thukuhar, was distinctly different from that of its unparasitized counterpart. The combined data suggest that, probably at the expense of muscle glycogen, the rootlet-infiltrated hepatopancreas of a parasitized host synthesizes and accumulates glycogen and triacylglycerol, which are longitudinally transported to the externae of the parasite.

We show that parasitization of $M$. thukuhar by Polyascus plana significantly altered levels of tissue and hemolymph metabolites of the host. First, in parasitized $M$. thukuhar, a significant hyperglycemic response was observed. Such a response has been recorded in other studies of rhizocephalan-parasitized crustaceans, including the red king crab Paralithodes camtschatica, the golden king crab Lithodes aequispina, and the shore crab Carcinus maenas (Shirley et al. 1986, Powell \& Rowley 2008). Moreover, parasitized $M$. thukuhar had significantly lower glycogen levels and higher glucose levels in the muscle. The hyperglycemia observed in parasitized hosts might be the result of an increased rate of glycogenolysis, a decreased rate of glycogen synthesis, or both in muscles. Interestingly, in the study of C. maenas, the authors speculated that the elevated glucose levels in the hemolymph of parasitized hosts was due to mobilization of glucose from the depositories of glycogen (Powell \& Rowley 2008); as there was no significant change in hepatopancreas glycogen levels, they further suggested that muscle was the primary source from which hemolymph glucose was mobilized (Powell \& Rowley 2008). In contrast to the muscle, the hepatopancreas of parasitized M. thukuhar had significantly higher levels of glycogen and triacylglycerol. It has also been shown that the liver (hepatopancreas) of C. maenas parasitized by Sacculina has higher levels of fat (Smith 1911). Glucose, presumably mobilized from the muscle as mentioned above, may have been used as a substrate for the synthesis of triacylglycerol and glycogen in the hepatopancreas of parasitized crabs.
The metabolic changes in the hepatopancreas in response to parasitization may reflect the effects of nutrient-energy drain exerted by the parasite on hosts. Our data show that significant levels of glycogen and triacylglycerol were accumulated in the externae. Although the mechanism of longitudinal transport that delivers the absorbed nutrients from rootlets to the externae is not precisely known, externae rely on rootlets for the supply of nutrients (Bresciani \& Høeg 2001). Indeed, histological and ultrastructural characteristics of rootlets suggest that the epidermal and axial cells are sites of synthesizing and storing nutrients and energy reserves (e.g. lipids, glycogen; Payen et al. 1983, Bresciani \& Høeg 2001). Thus, one of the explanations for the increased levels of glycogen and triacylglycerol in the rootlet-infiltrated hepatopancreas may be the mobilization of resources by the parasites.

Major effects of parasitization by sacculinid rhizocephalans on the host were manifested through changes in the endocrine system of the host (see Høeg 1995, O'Brien 1999). For example, hemolymph levels of ecdysteroids were lower and the Y-organ (an ecdysteriodogenic gland) regressed in parasitized hosts (Andrieux \& Wolff 1974, Andrieux et al. 1976, 1981, Chassard-Bouchaud \& Hubert 1976). We found no obvious morphological changes in eyestalk X-organ/sinus gland complex of parasitized $M$. thukuhar. In addition, levels of $\mathrm{CHH}$, an important metabolic hormone that is involved in carbohydrate and lipid metabolism (Santos \& Keller 1993, Webster et al. 2012), in the sinus glands were not significantly different between unparasitized and parasitized crabs. These data together suggest that, at least for the eyestalk neuroendocrine system, its gross structure and function (in terms of hormone production and storage) are not significantly impaired by parasitization. However, results of previous histological studies suggested that sacculinization led to reduction in the storage of neurosecretory substance in the sinus gland and inhibition of its discharge in C. maenas and C. mediterraneus (Rubiliani \& Payen 1979). Future studies could be directed towards determining circulating $\mathrm{CHH}$ levels using a more sensitive immunoassay (e.g. a sandwich-type ELISA) in order to demonstrate the effect of parasitization on the release pattern of $\mathrm{CHH}$. Knowledge regarding crustacean endocrinology acquired during the past few decades (for reviews, see Hopkins 2012, Webster et al. 2012) could serve as an important foundation for in-depth understanding of the mechanisms through which rhizocephalans control their hosts. 
Acknowledgements. We thank Yi-Chun Tien, Shih-Fu Tsai, and Bo-Jiang Chen, (Department of Biology, National Changhua University of Education) for providing assistance. This study was supported financially by the Ministry of Science and Technology through grants MOST 103-2311-B018-001 and 104-2311-B-018-002 to C.Y.L.

\section{LITERATURE CITED}

Andrieux N, Wolff ME (1974) The effect of ecdysterone on the molting of healthy crabs, Carcinus mediterraneus, and those parasitized by Sacculina carcini. C R Acad Sci Hebd Seances Acad Sci D 279:807-810

Andrieux N, Porcheron P, Berreur-Bonnenfant J, Dray F (1976) Determination of the ecdysone level in the molting cycle of the crab, Carcinus maenas: comparison between healthy individuals and those parasitized by Sacculina carcini. C R Acad Sci Hebd Seances Acad Sci D 283:1429-1432

Andrieux N, Herberts C, De Frescheville J (1981) The relationship between host and parasite in the crustacean Carcinus parasitized by Sacculina carcini: effect of crude extracts of Sacculina and haemolymph of parasitized crab upon the proteinogramm of experimented healthy crabs. Ann Parasitol Hum Comp 56:441-448

$>$ Bresciani J, Høeg JT (2001) Comparative ultrastructure of the root system in rhizocephalan barnacles (Crustacea: Cirripedia: Rhizocephala). J Morphol 249:9-42

Chang CC, Tsai TW, Hsiao NW, Chang CY, Lin CL, Watson RD, Lee CY (2010) Structural and functional comparisons and production of recombinant crustacean hyperglycemic hormone $(\mathrm{CHH})$ and $\mathrm{CHH}$-like peptides from the mud crab Scylla olivacea. Gen Comp Endocrinol 167:68-76

Chassard-Bouchaud C, Hubert M (1976) On the fine structure of the regressing ecdysial glands of Carcinus maenas L. (Crustacea Decapoda) parasitized by Sacculina carcini Thompson. Cell Tissue Res 167:351-361

Chen HY, Watson RD, Liu HF, Chen JC, Lee CY (2007) Molecular characterization and gene expression pattern of two molt-inhibiting hormone-like peptides from Litopenaeus vannamei. Gen Comp Endocrinol 151:72-81

Drilhon A (1936) Quelques constantes chimiques et physicochimiques du milieu intérieur de crabe sacculiné, Carcinus moenas. C R Acad Sci Paris 202:981-982

> Glenner H (2001) Cypris metamorphosis, injection and earliest internal development of the Rhizocephalan Loxothylacus panopaei (Gissler). Crustacea: Cirripedia: Rhizocephala: Sacculinidae. J Morphol 249:43-75

Glenner H, Høeg JT (1995) A new motile, multicellular stage involved in host invasion by parasitic barnacles (Rhizocephala). Nature 377:147-150

> Glenner H, Høeg JT, O'Brien JJ, Sherman TD (2000) Invasive vermigon stage in the parasitic barnacles Loxothylacus texanus and L. panopaei (Sacculinidae): closing of the rhizocephalan life-cycle. Mar Biol 136:249-257

Glenner H, Lützen J, Takahashi T (2003) Molecular and morphological evidence for a monophyletic clade of asexually reproducing Rhizocephala: Polyascus, new genus (Cirripedia). J Crustac Biol 23:548-557

> Høeg JT (1995) The biology and life cycle of the Rhizocephala (Cirripedia). J Mar Biol Assoc UK 75:517-550

Hopkins PM (2012) The eyes have it: a brief history of crustacean neuroendocrinology. Gen Comp Endocrinol 175: 357-366
Hsu HM (2014) Parasitic situation and external developmental stage of Polyascus plana (Cirripedia: Rhizocephala) parasite on Metopograpsus thukuhar from Northern Taiwan. MSc thesis, National Taiwan Ocean University, Keelung

Huang JF, Lützen J (1998) Rhizocephalans (Crustacea: Cirripedia) from Taiwan. J Nat Hist 32:1319-1337

Johnson PT (1980) Histology of the blue crab, Callinectes sapidus. A model for the Decapoda. Praeger Publishers, New York, NY

Lee CY, Yang PF, Zou HS (2001) Serotonergic regulation of crustacean hyperglycemic hormone secretion in the crayfish, Procambarus clarkii. Physiol Biochem Zool 74: 376-382

Liu HC, Lützen J (2000) Asexual reproduction in Sacculina plana (Cirripedia: Rhizocephala), a parasite of six species of grapsid crabs from Taiwan. Zool Anz 239:277-287

O'Brien JJ (1999) Parasites and reproduction. In: Pearse J (ed) Encyclopedia of reproduction, Vol 3. Academic Press, New York, NY, p 638-646

O'Brien J, van Wyk P (1985) Effects of crustacean parasitic castrators (epicaridean isopods and rhizocephalan barnacles) on growth of crustacean hosts. In: Wenner A (ed) Crustacean growth: factors in adult growth. Crustacean issues 3. A.A. Balkema, Rotterdam, p 191-218

Pantin CFA (1934) On the excitation of crustacean muscle. J Exp Biol 11:11-27

> Payen GG, Rubiliani C, Hubert M, Poulhe R, Turquier Y, Chassard-Bouchaud C (1983) Mise en évidence des fonction de synthèse, d'absorption et de transfert de substance par les racines des Rhizocéphales Sacculinidae; premières données biochemiques et cytochemiques. Z Parasitenkd 69:255-269

Powell A, Rowley AF (2008) Tissue changes in the shore crab Carcinus maenas as a result of infection by the parasitic barnacle Sacculina carcini. Dis Aquat Org 80:75-79

Rubiliani C, Payen GG (1979) Modalités de la destruction des régions neurosécrétrices des crabes Carcinus maenas (L.) et C. mediterraneus Czerniavsky infestés par la sacculine. Gen Comp Endocrinol 38:215-228

Santos EA, Keller R (1993) Crustacean hyperglycemic hormone $(\mathrm{CHH})$ and the regulation of carbohydrate metabolism: current perspectives. Comp Biochem Physiol A Physiol 106:405-411

> Shirley SM, Shirley TC, Meyers TR (1986) Hemolymph responses of Alaskan king crabs to rhizocephalan parasitism. Can J Zool 64:1774-1781

Smith G (1911) Studies in the experimental analysis of sex. Part 7. Sexual changes in the blood and liver of Carcinus maenas. Q J Microsc Sci 57:251-265

Tsai KW, Chang SG, Wu HJ, Shih HY, Chen CH, Lee CY (2008) Molecular cloning and differential expression pattern of two structural variants of the crustacean hyperglycemic hormone family from the mud crab Scylla olivacea. Gen Comp Endocrinol 159:16-25

Tu TH, Chan BKK, Jeng MS (2009) Larval development and sex ratio variation of Polyascus plana (Cirripedia: Rhizocephala), a parasite of the crab Grapsus albolineatus, in Taiwan. Bull Mar Sci 84:331-349

- Walker G (2001) Introduction to the Rhizocephala (Crustacea: Cirripedia). J Morphol 249:1-8

Webster SG, Keller R, Dircksen H (2012) The CHH-superfamily of multifunctional peptide hormones controlling crustacean metabolism, osmoregulation, moulting, and reproduction. Gen Comp Endocrinol 175:217-233 